\title{
Obesity decreases hepatic cytochrome p450 expression
}

\section{Short communication}

Currently, more than one-third of the US population is obese, causing higher rates of diabetes, cardiovascular and liver diseases and mortality. Despite this, there is a lack of translational research studying the effects of obesity on hepatic detoxification and drug metabolism. This study focuses on the effects of obesity on the expression of the cytochromes P450 (P450), the major enzyme family in drug metabolism. We hypothesized that obesity may alter liver metabolism and detoxification through decreased expression of P450s. Protein expression was quantified with Western Blots using pooled (ideal weight, $n=15$; overweight, $n=10$; obese, $n=10$; morbidly obese, $\mathrm{n}=5)$ and individual $(\mathrm{n}=52)$ samples based on BMI (ideal weight, overweight, obese and morbidly obese). The isoforms CYP1A2, 2C9, 2E1 and 3A4 were studied. Preliminary results suggest a decreasing trend in expression with obesity, with CYP2C9 being statistically significant (one-way ANOVA, $\mathrm{P}<0.001$ ). Morbidly obese samples showed to be always the lowest in protein expression. The exception was CYP2E1 where protein expression increased with obesity. Since P450 protein expression generally decreases in obesity, this may also lead to lower enzyme activity and clearance. Globally, obese patients require more medical care and doses of medication than healthy individuals, rendering them prone to adverse drug reactions. Ultimately, understanding the relationship between obesity and

\author{
Volume 3 Issue 3 - 2016
}

\section{Ron Arleigh C Tamayo}

Department of Tropical Medicine, Medical Microbiology and Pharmacology, University of Hawaii, USA

Correspondence: Ron Arleigh C.Tamayo, Creighton University, 2500 California Plaza Omaha, NE 68I 02 USA, Tel 808258930I, Email rctl486I@creighton.edu

Received: January 05, 2015 | Published: January II, 2016

hepatic detoxification can improve medical and dietary interventions to prevent morbidity and mortality in the obese population.

\section{Acknowledgements}

None.

\section{Conflict of interest}

Author declares that there is no conflict of interest. 